\title{
Research on The Design of Xiamen's Urban Visual Identity System
}

\author{
Zhu Wen \\ dept. Xiamen University Tan Kah Kee College \\ China
}

\begin{abstract}
As a visual communication design of urban brand, urban visual identity is widely used in today's society. Starting with the Xiamen's urban identity design, this paper deduces the Xiamen's urban identity design through analyzing the cultural connotation and orientation of Xiamen. Furthermore, it puts forward that the Xiamen's urban identity design plays an effective role in urban identity propaganda.
\end{abstract}

Keywords-City identity; Xiamen; Urban visual identity; Urban positioning

\section{INTRODUCTION}

A city is the consequence under the development of social productivity, which symbolizes the development of human civilization. City image is not an independent existence, but as an aesthetic object relative to the aesthetic subject. The manifestation of city image has a direct impact on the life of urban people, on the expansion of urban economy and urban products, and the creation of urban core competitiveness. The visual urban design is the most powerful communication capacity in City Identity System, which can demonstrate the visual transmission directly and effectively. Even with its unique urban personality and regional cognition, Xiamen is facing the test of the new era. We should redefine its urban cultural style and attributes, so as to implement the design of VI system with cultural characteristics, and build the unique city vision image and vision symbol of Xiamen.

\section{URBAN CULTURAL CONNOTATION AND IDENTITY ORIENTATION OF XIAMEN}

As a modern international port and scenic tourist city, Xiamen is known as the "Marine Garden". On October 23, 1986, at the 23rd meeting of the Standing Committee of the Eighth People's Congress of Xiamen, Phoenix Tree is identified as city tree, Triangle Plum as the city flower, and Egret as the city bird.

\section{A. Urban Cultural Connotation of Xiamen}

"Connotation" is an abstract feeling, a kind of person's cognition of things or people, it hides in the depths of things and needs to be explored by people. "Culture" can be divided into two kinds: narrow sense and broad sense. The narrow sense refers to philosophy, religion, art, politics, ethics, etc.; While in the broad sense, it refers to all things created by spiritual and material civilization. In the following paragraphs, the author will come out the urban cultural connotation of Xiamen from the aspects of urban overview, history, culture,

Project: 2018 Fujian Education and Research Development Project of Young and Middle Aged Teacher (JAS180837). customs and food culture, and strive to understand the characteristics of Xiamen's urban identity more accurately through the generalization and grasp of Xiamen city connotation, so as to lay a groundwork for design.

\section{1) General information}

Located on the southeast coast of China, Xiamen is one of the first special economic zones to open to the outside world. It is connected with Zhangzhou and Quanzhou to become the Minnan Golden Triangle. It is composed of six administrative regions: Xiamen Island, Gulangyu Island, Tongan, Jimei, Haicang and Xiang 'an. The land area is 1565.09 square kilometers and the sea area is more than 300 square miles. Xiamen has a population of 3531347 , of which $52.25 \%$ is a foreign population. The language spoken in Xiamen is Minnan, and the population of $58 \%$ is in Minnan. The local climate is subtropical monsoon climate with an average annual temperature of about $21^{\circ} \mathrm{C}$.

\section{2) Historical culture}

Xiamen was originally an isolated island surrounded by the sea. According to legend, groups of egrets often inhabit the island, therefore, its other name is Lu Island. The strait between Xiamen and Gulangyu is called Lujiang. According to archaeological data, as early as the Paleolithic era, ancient people lived on the island. In the middle of the Tang Dynasty, the Han people entered the island for pioneering. Xiamen was named "Jiahe" in Dazhong of the Tang Dynasty, and its name originated from people's hard work for hundreds of years and allowed wasteland to grow rice. Xiamen in the Song Dynasty is only an unimportant part of Tongan County, and was called "Jiaheli" and "Jiaheyu" at that time. During the third-year of Jiayou in Song Dynasty, the Song Dynasty regime stationed troops on the island. Since then, the military status of the island has been valued. In the Yuan Dynasty, Xiamen still belonged to the jurisdiction of Tongan County. In the early Ming Dynasty, Zhu Yuanzhang sent Zhou Dexing to the nearby coast to establish a yamun and build a city. In the twenty-seventh year of Hongwu, the Ming Dynasty government completed the construction of the city on the island and named it "Xiamen City". From then on, Xiamen was recorded in history. In the four-year of Shunzhi in the Qing Dynasty, Zheng Chenggong stationed in Gulangyu and was stationed on Xiamen Island for seven years. In the 12 th year, he renamed Xiamen as "Siming Canton". The term "Siming" is still in use today. In the twentyyear of Daoguang, the first Opium War was launched in Britain, Xiamen was forced to be one of the first five trading port cities in China. In 1852, the British Concession was established on Xiamen Island. In 1902, Gulangyu became a public concession. Until October 4, 1945, the Nationalist government resumed the 
establishment of Xiamen City. On October 17, 1949, Xiamen was liberated. Xiamen has the superior channel nature of natural harbor. The first batch of Chinese tea that appeared on the European market was exported by the Dutch from Xiamen. Its English name is written as "Tea" because it is the pinyin of the Xiamen dialect.

\section{3) Customs}

Like the Han areas throughout the country, Xiamen pays attention to traditional festivals, while it is different from those in many regions for the specific forms of certain traditional customs. For example, during the Spring Festival, the family must eat Chinese New Year's Eve dinner together; Light firecrackers in the early morning of the first day and put on new clothes to worship the New Year. If you meet friends and relatives on the way, you must congratulate each other; On the third day of the year, you can not come to the door, because it is a new day to chase the sadness for new death away; Lantern Festival, on the 15th of the first month, is called "Shangyuan" or "Lantern Festival" by Xiamen. In the evening, parents take their children to the lantern festival with lanterns. Ching Ming Festival, people sweep tombs and worship ancestors; Dragon Boat Festival, Xiamen commonly known as "five days." The door is inserted with Aipu, and the realgar is sprinkled at home, children are accompanied by sachets, eating dumplings and racing dragon boats; For Xiamen, the Mid-Autumn festival is the most important holiday besides the spring festival. In addition to enjoying the moon and eating moon cakes, people also play a traditional game named pissa; Chung Yeung Festival, folk people like hiking excursions; In the winter solstice, every household needs to worship ancestors and eat dumplings. There are also some special ceremonial customs in Xiamen folk. For example, beating people with a broom is regarded as the greatest insult; The behavior that the owner sweeps the floor while the guest is still in the seat is considered to be expelling the guest; In the wedding banquet, breaking the tableware is not allowed; When eating, it is wrong to stick chopsticks on the rice; When entertaining guests, setting six dishes is taboo; In custom, people can not give the umbrellas as gifts.

\section{4) Diet culture}

The Chinese food culture can be described as extensive and profound, with a long history. The same is true of Xiamen's food culture. Since people moved to Xiamen in the Tang Dynasty, people from the Song, Yuan, Ming and Qing dynasties have settled in Xiamen. With the historical background of Xiamen's expansion of foreign trade, experience of the Opium War, opening up foreign trade, and even the fall of the country, cooking techniques have also been introduced in various places, and various factors have combined to promote Xiamen's unique diversified cuisine. People can further understand the life of Xiamen people and the local folk customs culture by tasting the local flavor dishes in Xiamen.

Due to its unique geographical environment and climatic conditions, Xiamen is rich in seafood. In addition to seafood, medicinal meals and South Putuo vegetarian dishes are also representatives of Xiamen cuisine. Xiamen cuisine is mainly cooked by steaming, frying, stir-frying, quick-frying, deepfrying, and stew. The most important component of the Xiamen diet is Xiamen snacks which reflect the imagination and creativity of Xiamen people, with rich variety. There are more than 200 kinds of most famous Xiamen snacks, including sand and tea noodles, buns, bamboo shoots, sea Bream, spring rolls, and batter.

The connotation of Xiamen's urban culture embodies Xiamen's historical heritage, aesthetic taste and moral value. It contains the deepest spiritual pursuit and code of conduct.(1) There are obvious differences in the cultural connotation between different cities, at the same time, the passage of time has marked the history of diverse cities. Xiamen's history and culture has its unique cultural personality and is a valuable resource for the city. The urban visual identity design of Xiamen can extract the elements from the history and culture and form the core of the city brand to help the accurate positioning of the urban identity and the design and application of the city identity vision.

In addition, in the dynamic design of the urban visual identity of Xiamen, the animation script also extracts its cultural connotation as the background of the story. For example, it briefly introduces the urban situation of Xiamen, the resident population, the language, and the climate, analyzes the reasons for the alias "Lu Dao", tells vivid historical stories such as the first Opium War period and the source of the English name of "Tea", summarizes the distinctive local cultural customs and characteristic dietary culture, and embodies the perfect combination of form and content in design and practice.

\section{B. Xiamen's urban identity positioning}

Urban identity positioning refers to the city's correct and clear understanding of the urban identity 's goal, role and competitive position in urban development according to its own conditions. The positioning of urban identity needs to highlight the individuality of the city. Due to the different geographical location and cultural traditions of each city, its historical and cultural characteristics should be considered in urban identity design to create a distinctive urban identity. The following is the positioning of the city by the government and relevant scholars. The author makes some combing to find the content that meets the requirements of Xiamen urban identity design from many positions.

The positioning of the economy. There are three major favorable conditions for Xiamen's economic development: First Xiamen has superior geographical conditions. It not only has a rare natural harbor, but also faces Taiwan across the Taiwan Strait. And it has the same special relationship with Taiwan, which is related to blood, language, and customs; The third is the increasingly perfect financial market.

The positioning of the history. This land of Xiamen has rich and heavy historical accumulation and cultural connotation. In the Neolithic Age four or five thousand years ago, there were traces of early human life on Xiamen Island. About 1200 years ago in the middle of the Tang Dynasty, the Central Plains Han nationality moved to Xiamen to relocate and prosper on the island. In the twenty-seventh year of Hongwu (1394), the castle was built here and named Xiamen City. Since then, the name of "Xiamen" has officially appeared on the territory of the motherland. With the progressive development of the city and 
the continuous improvement of its popularity, it has gradually become famous at home and abroad. Today, Xiamen is no longer a remote and desolate fishing village on the island, but a famous special economic zone, a modern international port scenic tourist city at home and abroad.

The positioning of the education. Successive governments of Xiamen attach great importance to education, all of which care, support and develop education from such aspects as increasing investment in education, formulating educational policy rules and constructing a good education atmosphere. In 1993, the idea of building Xiamen into a "city of education", is proposed, when the plans are formulated and gradually implemented.

The positioning of the transportation. Xiamen has extremely convenient transportation conditions, and the sea-airland infrastructure is well developed. There are two major highways and four railway lines cross through. The passenger throughput of Gaoqi International Airport in 2007 and 2008 ranked 11th in domestic civil aviation airports. Xiamen Port is an important hub of China's comprehensive transportation system, and is also an important port for Taiwan shipping and an important port for "three links". On December 15, 2008, the three agreements signed by the Cross-Strait Relations Association and the Straits Exchange Foundation for direct shipping, direct air transport, and direct mail on both sides are formally implemented.

The positioning of the tourism. a) Marine Garden. Gulangyu has a pleasant climate, with songs of birds and scent of flowers, and is known as the "Marine Garden". (b) The island of music. Gulangyu has the only piano museum in the country. There are more than 5,000 pianos on the island, simultaneously, it has the world's earliest four-corner piano and the earliest and largest vertical piano. The Gulangyu Piano Festival is held regularly every year. c) World Architecture Exhibition. "For historical reasons, the small island of Gulangyu has gathered architectural buildings of different and Chinese and Western combined styles. For example, the traditional temples with Chinese cornices and the courtyard bungalows in the southern style, the Diagrams Building which is called as 'Little White House', the little and dainty Japanese houses and the Western consulate in European style built in19th century, etc., it can be said that Gulangyu is an architectural encyclopedia, which has experienced more than one hundred years of vicissitudes and has become a valuable and important resource."

Through the above arrangement of the cultural connotation and identity orientation of Xiamen, the historical culture and tourism culture of Xiamen are regarded as the important resources to distinguish other cities. Therefore, these two aspects as Xiamen visual identity design in the design material has been emphatically extracted. The history and culture are the city memories of Xiamen and the guarantee of the sustainable development of urban culture. Thinking and shaping the identity of the city from the perspective of historical and cultural orientation can improve the connotation and taste of the city and show its individuality and charm. As an international tourist city, Xiamen attracts a large number of tourists due to its pleasant climate, abundant tourist resources and marathon competitions. The goal of Xiamen government is to develop tourism into a pillar industry of Xiamen's national economy, and to build Xiamen into a comprehensive, multifunctional and modern international tourist city. Therefore, the prominence of its important position in Xiamen's urban identity design helps to show the charm of Xiamen's tourism, while other positions on education and transportation play an auxiliary role in identity design.

The refinement of Xiamen's urban connotation, the determination of urban positioning, and the determination of the development advantages of Xiamen have laid a solid foundation for the design of Xiamen's urban identity.

\section{URBAN VISUAL IDENTITY OF XIAMEN}

The Urban Visual Identity (VI) is the communication and visualization part of the urban identity. It is the most direct and effective way to establish and promote the city's popularity and establish the city's brand image. It expresses the spiritual idea of the city through the visual form, embodies the difference of the city, and highlights the personality characteristics of the city. According to the positioning analysis of the identity of Xiamen, the design practice of Xiamen's urban logo, color and application part is derived.

\section{A. The design concept of Xiamen logo}

The logo of Xiamen is designed through the analysis of the cultural connotation and orientation of Xiamen, combined with public demand, the use of abstract graphics and text of the combination of the expression, with the combination of the letter " $\mathrm{X}$ " and the flying egrets.

The logo is represented by the Latin alphabet "X". As the most widely circulated letter in the world, the Latin alphabet has become the most common alphabet in the world because of its simple and clear form and easy identification. Most countries in the West and Chinese pinyin have used the Latin alphabet. "X" is the first letter of the pinyin of "Xiamen", the advantages of its application can improve the recognition and popularization of the logo, and it is just right to be the symbol of a modern international scenic tourist city; While the Egret is the city bird of Xiamen, although there are doubts about the legend of the Egret, the geographical location and climatic conditions of Xiamen Island are suitable for the life habits of egrets, and have the superior conditions for the egrets to inhabit. Although the modernization of Xiamen destroyed the ecology in the 1980s and 1990s, the egret left Xiamen, people later raised their awareness of environmental protection. On October 23, 1986, at the 23rd meeting of the Standing Committee of the Eighth People's Congress of Xiamen, the Egret was identified as a city bird to increase the public's awareness of environmental protection. Since then, careful care of this white elf has become a conscious action of the public, deeply affecting the lives of the people. Therefore, the egret is of great significance to the people of Xiamen, but also can obtain a general sense of identity. The flying posture of Egret is abstractly graphical, and is integrated into the " $\mathrm{X}$ " letter, the two complement each other to form the whole of the logo, which is not only a representative of Xiamen, but also can awaken human awareness of urban environmental protection. 
B. Application of the standard color of Xiamen's urban visual identity

The standard colors of Xiamen urban visual identity: Blue (R10 G176 B225) (C71 M7 Y5 KO), red (R221 G2 B53) (C6 M100 Y74 K1), orange (R238 G118 B7) (CO M66 Y96 KO). Wherein, blue comes from the intuitive human feelings of the blue things of nature, and is reminiscent of the sea, the sky and the universe, symbolizing peace and happiness, but also represents a broad mind and a harmonious world, and represents the sea and history in Xiamen's urban identity design; Red, as the spiritual conversion of the Chinese people, has gradually evolved into a traditional Chinese philosophy and cultural heritage, representing auspiciousness, happy, nobility, grandeur and so on, symbolizing the enthusiasm, unrestrainedness and passion. In the Xiamen's urban identity, it symbolizes custom; Orange is a cheerful and lively color, belonging to a warm color, symbolizing vitality, joy and Buzz. In Xiamen's urban identity, Orange is used to symbolize food, the bright warm color of orange in food has an effect of increasing appetite.

\section{Application part of Xiamen's urban visual identity elements}

The application of Xiamen's urban visual identity elements is also carried out in accordance with the basic parts of the logo, standard fonts, standard colors and standard graphics, and is applied to tourist souvenirs, printed publications, city propaganda films and so on in strict accordance with the combination of basic parts. Tourist souvenirs include postcards, shopping bags, refrigerator stickers and so on, and the printed publications include leaflets, brochures, books and so on. Among them, the city propaganda film brings together the design elements of city logo, icon, colors and fonts in the form of dynamic manifestation, which is connected with the storyline. It embodies the dynamic achievements of urban visual pictographic, and strengthens the intensity of visual communication of urban identity.

\section{CONCLUSION}

The Xiamen's urban visual identity integrates the urban cultural connotation and identity orientation of Xiamen, and highlights the advantages of urban historical culture and tourism resources. It promotes the development of urban tourism and investment environment, while raising public awareness of urban identity and urban environmental protection.

\section{REFERENCES}

[1] An Yunhua. An Analysis of Urban Culture and Urban identity. Chinese and Overseas Architecture. 2006(5). (In Chinese)

[2] Hong Buren. Xiamen History and Land, Prepared by the Chinese People's Political Consultative Conference in Xiamen, Fujian Province, Xiamen University Press, 2007. (In Chinese)

[3] Tan Nanzhou. Brave Reform, Sustainable Development and Construction of Education City -- Review and Outlook on Xiamen Educational Reform and Development. Journal of Lujiang University,2000(1). (In Chinese)

[4] Wang Yi. Three Direct Links Writes A New Chapter In History, Integrated Transportation, 2009(1). (In Chinese) 